\title{
Esophageal reconstruction by substernal route: impact of the thoracic inlet enlargement on cervical anastomotic complications: leak and stricture
}

\begin{abstract}
Introduction: The mediastinal route is preferred four immediate reconstructions after esophagectomy however the substernal approach is used for delayed construction. The substernal route is an alternative option for reconstruction however this approach has a major disadvantage which is the potential risk of graft compression at the level of thoracic inlet.This prospective study aims to evaluate whether the enlargement of the thoracic inlet during substernal colonic interposition can influence the incidence of cervical anastomotic complications
\end{abstract}

Patients and methods: During a prospective study conducted from 2005 to 2015 at our institution, 77 substernal colonic interposition were performed for esophageal caustic stricture. The surgical procedure used in all patients was a left isoperistaltic colon graft interposed by substernal route. The thoracic inlet was enlarged by removing the left half of manubrium and internal third of left clavicle. The patients were divided into two groups. G1with enlarged thoracic inlet and G2 without enlargement. The parameters such leakage and stricture of cervical anastomosis, length of hospital stay, graft necrosis, operative time , blood transfusion and blood loss were compared between the two groups. The integrity of oesophagocolic anastomosis was postoperatively assessed by barium study.

Statistical analysis: The primary outcome of this study was the incidence of leakage and stricture of cervical anastomosis. The secondary outcome was graft necrosis, blood loss, blood transfusion, operative time and the length of hospital stay. The Pearson chisquare test, Fisher's exact test and Student t-test were used to perform statistical analysis. A $\mathrm{P}$-value of less than 0.05 was considered significant. The statistical results were expressed by $95 \%$ confidence intervals.

Results: In group 1, there were 28 women and $10 \mathrm{men}$. The mean age of patients was 28.44years. The mean blood loss was $273.6 \mathrm{ml}$. The mean blood transfusion unit was 1.42 The mean operative time was $170.52 \mathrm{mn}$. One patient experienced graft necrosis. Cervical anastomotic leakage was occurred in 4 patients. Two patients developed cervical anastomotic stricture. The mean hospital stay was 18.13 days. In group 2, there were 31 women and 8 men. The mean age of patients was 24.79 years. The mean blood loss was $315.68 \mathrm{ml}$. The mean blood transfusion unit was 1.10 . The mean operative time was $312 \mathrm{mn}$. Graft necrosis was occurred in 2patients. Eleven patients developed cervical leakage.Cervical anastomotic stricture was occurred in 6 patients. The mean hospital stay was 22.07 days. The operative death was occurred in two patients. The incidence of leakage was significantly lower in G1 than in $\mathrm{G} 2(10.5 \%$ vs $15 \%$ respectively ; $\mathrm{P}=0.0462)$. The operative time and the hospital stay were significantly longer in $\mathrm{G} 2(\mathrm{p}=0.00172, \mathrm{p}=0.0132$ respectively). No significant statistical differences were found in parameters such as age, gender, blood loss, blood transfusion, necrosis, cervical anastomotic stricture and hospital stay in two groups.

Conclusion: The study findings showed that the enlargement of the thoracic inlet during substernal esophageal reconstruction had reduced the cervical anastomotic leakage without impact on operative time or additional risk of complications. When using the substernal approach, we feel it is beneficial to enlarge the thoracic inlet by removing the left half of the manubrium and the sternal head of the left clavicle.

Keywords: esophageal reconstruction, left colon graft, substernal route, cervical leak, thoracic inlet enlargement

\author{
Volume 5 Issue 7 - 2016
}

\author{
Boukerrouche Abdelkader \\ Department of general Surgery, University of Algiers, Algeria
}

Correspondence: Boukerrouche Abdelkader, Department of general Surgery, hospital and university centre of Beni-Messous, University of Algiers, Algiers, Algeria, Tel +213 66I 2272 98, Fax +21321931310, Email aboukerrouche@yahoo.com

Received: October 31, 2016 | Published: December 28, 2016

\section{Introduction}

The two most used routes for esophageal reconstruction are the posterior mediastinum and substernal space. The médiastinal route is preferred for immediate reconstruction after esophagectomy however the substernal approach is used for delayed construction.

The disadvantages of the posterior mediastinal route have prompted some surgeons to advocate an alternate route of reconstruction, namely the substernal approach. The substernal approach for esophageal reconstruction was used firstly by Dale and Sherman in. ${ }^{1}$ The biggest disadvantage of the retrosternal approach is the potential compression risk of the graft at the site of the thoracic inlet, which can lead to mechanical ischemia. To prevent this event, some surgeons suggested the enlargement of the thoracic inlet by removing the left half of 
the sternal manubrium and the internal third of left clavicle. ${ }^{2-4}$ This prospective study aims to evaluate whether the enlargement of the thoracic inlet during substernal colonic interposition can influence the incidence of cervical anastomotic complications.

\section{Patients and methods}

\section{Patients}

A prospective study was conducted from 2005 to 2015 at our institution. Seventy seven substernal colonic interpositions were performed for esophageal caustic stricture. There were 59women and $18 \mathrm{men}$. The mean age of patient was 16.6years. Emergency total esophagogastrectomy was required in two patients. A gastroenteroanastomosis was performed before colonic interposition in 10patients because of early gastric stenosis.

\section{Methods}

The preoperative evaluation of the colon by colonoscopy was performed in 5patients. Preoperative angiography was performed only in one patient. Nutritional disorders were corrected using nutritional supports before surgery. The surgical procedure used in all patients was a substernal isoperistaltic left colonic interposition. The adequacy of colon graft blood supply was judged peroperatively by inspection, palpation, transillumination of the mesentery and vascular clamping test. It is important to take care of checking constantly the position of the graft vessels to ensure there is no mechanical compression that may impair the graft vascular supply and to select a graft with sufficient length avoiding thus tension at the anastomotic site. The cervical scarred esophageal was completely removed and the cervical anastomosis was performed on healthy tissue using an interrupted single-layer end-to-end hand-sewn anastomosis. The distal anastomosis was performed at the posterior side of the gastric antrum when the stomach is available. An early postoperative enteral nutrition via tube-jejunostomy was introduced 24hours after surgical procedure. The integrity of oesophagocolic anastomosis was postoperatively assessed by barium study between 8 th and $10^{\text {th }}$ day. The thoracic inlet was enlarged by removing the left half of manubrium and internal third of left clavicle, resection of the left half of the manubrium and the sternal head of the left clavicle (Figures $1 \& 2)$. The thoracic inlet was enlarged whenever it was judged too narrow and not allowing the easy passage of three hand fingers. The patients were divided into two groups. G1 with enlarged thoracic inlet and G2 without enlargement. Parameters such as incidence of leakage and stricture of cervical anastomosis, length of hospital stay, graft necrosis, operative time, blood transfusion and blood loss were compared between the two groups.

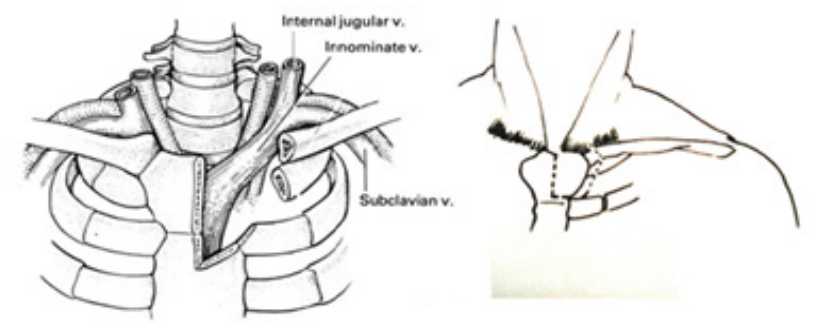

Figure I Excision of the left half of the manubrium and the head of the left clavicle.

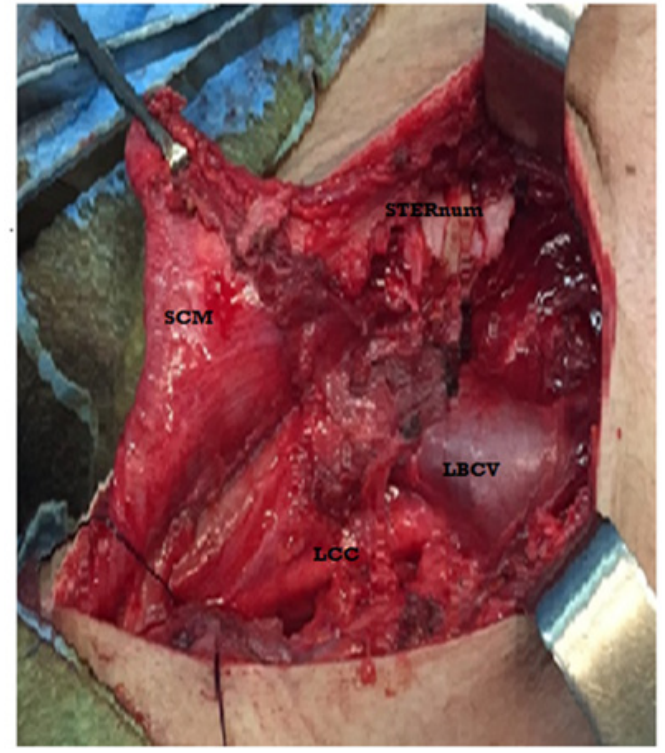

Figure 2 Operative view of enlarged thoracic inlet.

SCM, sternocleidomastoid muscle; LCC, left common carotid; LBCV, left brachiocephalic vein

\section{Statistical analysis}

The patients' baseline characteristics were compared. Proportions and percentages were used to summarize the categorical variables, whereas descriptive statistics with mean values $( \pm \mathrm{SD})$ were used for numerical variables. The primary outcome of this study was the incidence of leakage and stricture of cervical anastomosis. The secondary outcome was graft necrosis, blood loss, blood transfusion, operative time and the length of hospital stay. The Pearson chi-square test and Fisher's exact test were used to determine the statistical significance of each of the categorical variables. Student t-test was used to compare the mean values of the numerical variables between the two groups. A P-value of less than 0.05 was considered significant. The statistical results were expressed by $95 \%$ confidence intervals.

\section{Results}

IN group 1 with opening of thoracic inlet, there were 28 women and $10 \mathrm{men}$. The mean age of patients was 28.44 years (ranging 16 to 62 ). The median blood loss was $273.6 \mathrm{ml}$ (ranging 100 to 500 ). The median blood transfusion unit was 1.42 (ranging 0 to 5). The median operative time was $170.52 \mathrm{mn}$ (ranging 150 to 360 ). One patient experienced graft necrosis $(2.63 \%)$. Cervical anastomotic leakage was occurred in 4patients (10.5\%). Two patients $(5.3 \%)$ developed cervical anastomotic stricture. The mean hospital stay was 18.13 days (ranging 10 to 43) (Table 1). In group 2 without opening of thoracic inlet, there were 31 women and 8 men. The mean age of patients was $24.79 y$ years (ranging 16 to 49 ). The mean blood loss was $315.68 \mathrm{ml}$ (ranging 150 to 500 ). The mean blood transfusion unit was 1.10 (ranging 0 to 3 ). The mean operative time was $312 \mathrm{mn}$ (ranging 210 to 500). Graft necrosis was occurred in one patient (2.56). Eleven patients $(28.2 \%)$ developed cervical leakage. Cervical anastomotic stricture was occurred in 6 patients $(15 \%)$. The mean hospital stay was 22.07 days (ranging 13 to 47 ) (Table 1). The operative death, defined as death within 30 days following the operation, was occurred 
in two patients $(2.59 \%)$ (one death in each group). Graft necrosis was diagnosed on median postoperative day 2 (ranging 1 to 3 ). It was partial involving the proximal portion of graft. As confirmed by operative findings, the necrosis was the result of ischemia due to venous thrombosis. The leakage was treated conservatively in all patients and the spontaneous closure was obtained in all patients, after a median delay of 7 days (ranging 5 to 10 ). The cervical anastomotic stricture was treated successfully by endoscopic balloon dilation in 6 patients and reoperation was needed in 2 patients. No significant statistical differences were found in parameters such as age, gender, blood loss, blood transfusion, cervical anastomotic stricture in two groups ( $\mathrm{p}=0.00172, \mathrm{p}=0.0132$ respectively) (Table 1 ).

Table I Statistical analysis results

\begin{tabular}{|c|c|c|c|c|}
\hline Variable & GI(38) & G2 (39) & $P$ value & Significance \\
\hline Age & $28.44(16-62)$ & $24.79(16-49)$ & 0.142 & NS \\
\hline Gender & - & - & 0.134 & NS \\
\hline Blood loss & $173.6 \mathrm{ml}(100-500)$ & $315.68 \mathrm{ml}(150-500)$ & 0.618 & NS \\
\hline $\begin{array}{l}\text { Blood } \\
\text { transfusion }\end{array}$ & I. $42 \mathrm{u}(0-5)$ & I. $10 \mathrm{u}(0-3)$ & 0.623 & NS \\
\hline $\begin{array}{l}\text { Operative } \\
\text { time }\end{array}$ & $270.52 \mathrm{mn}(150-360)$ & $312 \mathrm{mn}(210-500)$ & 0.00172 & $\mathrm{~s}$ \\
\hline Necrosis & I (2.63) & I (2.56) & 0.74 & NS \\
\hline $\begin{array}{l}\text { Cervical } \\
\text { leakage }\end{array}$ & $4(10.55)$ & II (28.2\%) & 0.0462 & S \\
\hline $\begin{array}{l}\text { Cervical } \\
\text { stricture }\end{array}$ & $2(5.3 \%)$ & $6(15.4 \%)$ & 0.139 & NS \\
\hline $\begin{array}{l}\text { Hospital } \\
\text { stay }\end{array}$ & 18.13day (10-43) & 22.07 day (13-47) & 0.0132 & $\mathrm{~S}$ \\
\hline
\end{tabular}

u, unit.

\section{Discussion}

Preoperative colon evaluation is recommended in patients for whom a colon reconstruction was planned.So preoperative colonoscopy is recommended in patient with history of colon disease or older than 45years. This exam was performed in a very small percentage of patients because of the younger age of most patients. Angiography is very was helpful in outlining the vascular arcade of the intestinal segment to be interposed in patient who had previous colonic resection. Therefore preoperative angiography is recommended in patients who had previous colon surgery. This invasive exam was only done in one patient who had received a second colon reconstruction after failure of initial colon interposition. During colonic interposition, there are three options for the placement of the digestive conduit namely the posterior mediastinum, the substernal tunnel and the subcutaneous space. However the two most commonly employed routes are the posterior mediastinum and the substernal route. The use of the posterior mediastinum needs the ablation of the native esophagus. The access to the posterior mediastinum is difficult or technically not possible in some situations. ${ }^{5}$ Such as in case of esophageal caustic stricture, the scared esophagus adheres intimately to adjacent organs which make its dissection risky and haemorrhagic exposing the patient to an additional risk of complications. This disadvantage and others have prompted some surgeons to advocate an alternate route of reconstruction, namely the substernal approach. Therefore the substernal route has been an alternative route for reconstruction when the posterior mediastinum is not accessible. It is very easy to perform the substernal route without need to thoracic approach. Substernal approach is an ideal indication for esophageal palliative surgery and for caustic stricture when the scarred esophagus is left in place. The longer distance of reconstruction and the higher incidence of cervical anastomotic leakage compared with the posterior mediastinal approach have always hampered the wider use of substernal route. ${ }^{6,7}$ Cervical anastomotic leak has always been one of the major complications associated with the anterior reconstruction approach. Its incidence was higher than that of oesophageal reconstruction through the posterior mediastinum. ${ }^{8,9}$ and varied from 19 to $70 \%$ in reported studies. ${ }^{10-13}$ It has been reported that nearly $50 \%$ of cervical anastomotic leaks result from anastomotic strictures and therefore the subsequent need for chronic dilatations. ${ }^{14}$ Some authors have suggested that the increased risk of anastomotic leakage in patients who undergo retrosternal reconstruction is due to the additional length of reconstruction that is required if anastomosis is made over the neck and the tight angulation of the thoracic inlet with high risk of graft compression. ${ }^{15,16}$ Therefore the potential risk of graft compression at the level of thoracic inlet is the biggest advantage of the substernal route. Compression can impair the blood supply of graft leading to mechanical ischemia of the proximal portion of the graft and causing leakage or localized necrosis. The venous blood flow is very sensitive to mechanical obstacle and as reported in literature, venous stasis is the usual precipitating event for necrosis. ${ }^{17}$ To prevent this event, some surgeons suggested enlarging the thoracic inlet by removing the left half of manubrium and internal third of clavicle..$^{2-4,7,18,19}$ The results of this present study revealed a reduction of cervical anastomotic leakage rate which statistically significant $(10.55 \%$ vs $28.2 \%$ ) in patients who received a substernal reconstruction with opening of the thoracic inlet ( $\mathrm{p}=0.0462)$. However the enlargement of thoracic inlet did not have an impact on cervical anastomotic stricture $(\mathrm{p}=0.139)$. The substernal route has been considered to be inferior to posterior mediastinal approach as it was believed to be a longer route and associated with high rate of cervical anastomotic leakage. ${ }^{7,20}$ How to reduce the incidence of cervical anastomotic leaks has always been a priority for studies in the field of oesophageal surgery. Abo and colleagues, ${ }^{9}$ Orringer and Sloan. ${ }^{16}$ thought that the high rate of cervical leak in substernal esophageal reconstruction was caused by the increased pressure around the anastomosis stoma due to compression of the surrounding dense tissues, which compromises the blood supply in that region, leading to mechanical local ischemia and hypoxia. These authors expanded the thoracic inlet by resecting the manubrium sterni and the left sternoclavicular joint during the oesophageal reconstruction through the substernal approach. ${ }^{9,16,21} \mathrm{We}$ have not noticed a similar study to this one in literature and which investigated the impact of opening of the thoracic inlet on cervical anastomotic complications. As showed by the study findings, the operative time was more longer in G2 without enlargement therefore the enlargement of thoracic inlet did not have an impact on the surgical procedure time. The achievement of the thoracic inlet opening takes twenty minutes and as revealed by this study results, there was not an impact on the duration of the surgical procedure. Also there was no difference in term of blood loss and blood transfusion between two groups. Therefore this associated procedure was not haemorrhagic. The enlargement of the thoracic inlet by removing the left half 
of sternal manubrium and the head of left clavicle is not invasive, without risk of secondary complications and does not have an impact on operative time. In addition this procedure allows for sufficient access to the left internal thoracic vessels, which can be advantageous for successfully performing microvessel anastomosis when necessary. The surgical procedure was performed by the same surgeon (author) however this study has a limitation that it is not randomised trial.

\section{Conclusion}

The study findings showed that the enlargement of the thoracic inlet during substernal esophageal reconstruction had reduced the cervical anastomotic leakage without impact on operative time or additional risk of complications. In addition the opening of thoracic inlet facilitates the access to internal thoracic vessels when a vascular supercharge of graft is necessary When using the substernal approach, we feel it is beneficial to enlarge the thoracic inlet by removing the left half of the manubrium and the sternal head of the left clavicle.

\section{Acknowledgments}

None.

\section{Conflicts of interest}

The authors declare that there are no conflicts of interest

\section{Funding}

None.

\section{References}

1. Dale and Sherman. Interposition colique retrosternal. J Thorac Surg. 1995;29:344-356.

2. DeMeester TR, Johansson KE, Franze I, et al. Indications, surgical technique, and long-term functional results of colon interposition or bypass. Ann Surg. 1998;208(4):460-474.

3. Takushi Yasuda, Hitoshi Shiozaki. Esophageal Reconstruction with Colon Tissue. Surg Today. 2011;41(6):745-753.

4. Cattan P, Chiche P, Berney T, et al. Surgical approach by cervicosternolaparotomyn for the treatment of extended cervical stenoses after reconstruction for caustic injury. $J$ Thorac Cardiovasc Surg. 2001;122(2):384-386.

5. Casson AG, Porter GA, Veugelers PJ. Evolution and critical appraisal of anastomotic technique following resection of esophageal adenocarcinoma. Dis Esophagus. 2002;15(4):296-302.

6. Ngan SY, Wong J. Lengths of different routes for esophageal replacement. J Thorac Cardiovasc Surg. 1986;91(5):790-792.
7. Coral RP, Constant-Neto M, Silva IS, et al. Comparative anatomical study of the anterior and posterior mediastinum as access routes after esophagectomy. Dis Esophagus. 2003;16:236-238.

8. Tilanus HW, Hop WC, Langenhorst BL, et al. Esophagectomy with or without thoracotomy: is there any difference? J Thorac Cardiovasc Surg. 1993;105(5):898-903

9. Abo S, Fujiwara Y, Noto N. Sternal resection in cases of cancer of thoracic esophagus: method of esophageal reconstruction (in Japanese). Gekachiryou (Surg Therapy). 1974;30:597-601.

10. Urschel JD, Urschel DM, Miller JD, et al. A meta-analysis of randomized controlled trials of route of reconstruction after esophagectomy for cancer. Am J Surg. 2011;182(5):470-475.

11. Orringer MB, Marshall B, Stirling MC. Transhiatal esophagectomy for benign and malignant disease. $J$ Thorac Cardiovasc Surg. 1993;105(2):265-276.

12. Yoichi Hamai, Jun Hihara, Manabu Emi, et al. Esophageal reconstruction using the terminal ileum and right colon in esophageal cancer surgery. Surg Today. 2012;42(4):342-350.

13. Lerut T, Coosemans W, Decker G, et al. Anastomotic complications after esophagectomy. Dig Surg. 2002;19(2):92-98.

14. Orringer MB, Marshall B, Iannettoni MD. Eliminating the esophagogastric anastomotic leak with a side-to-side stapled anastomosis. J Thorac Cardiovasc Surg. 2002;119(2):277-288.

15. CattanP,ChicheP,BerneyT.Surgicalapproachbycervicosternolaparotomyn for the treatment of extended cervical stenoses after reconstruction for caustic injury. J Thorac Cardiovasc Surg. 2001;122:384-386.

16. Orringer MB, Sloan H. Substernal gastric bypass of the excluded thoracic esophagus for palliation of esophageal carcinoma. $J$ Thorac Cardiovasc Surg. 1975;70(5):836-851.

17. Abdelkader Boukerrouche. Isoperistaltic left colic graft interposition via a retrosternal approach for esophageal reconstruction in patients with a caustic stricture: mortality, morbidity, and functional results. Surg Today. 2014;44(5):827-833.

18. Cerfolio RJ, Allen MS, Deschamps C, et al. Esophageal replacement by colon interposition. Ann Thorac Surg. 1995;59(6):1382-1384.

19. Neville WE, Najem AZ. Colon replacement of the esophagus for congenital and benign disease. Ann Thorac Surg. 1983;36(6):626-633.

20. Ngan SY, Wong J. Lengths of different routes for esophageal replacement. J Thorac Cardiovasc Surg. 1986;91(5):790-792.

21. Abo S. Special issue on 'my surgery.' Sternal manubrium resection and anterior mediastinum esophageal reconstruction in cases of cancer of thoracic esophagus (in Japanese). Gekashinryo (Surg Therapy). $1975 ; 171102-171104$ 